University of Nebraska - Lincoln

DigitalCommons@University of Nebraska - Lincoln

July 1974

Heavy Particles in Therapy: An Application of Track Theory

Robert Katz

University of Nebraska-Lincoln, rkatz2@unl.edu

S. C. Sharma

University of Nebraska-Lincoln, sharma@uta.edu

Follow this and additional works at: https://digitalcommons.unl.edu/physicskatz

Part of the Physics Commons

Katz, Robert and Sharma, S. C., "Heavy Particles in Therapy: An Application of Track Theory" (1974). Robert Katz Publications. 126.

https://digitalcommons.unl.edu/physicskatz/126

This Article is brought to you for free and open access by the Research Papers in Physics and Astronomy at DigitalCommons@University of Nebraska - Lincoln. It has been accepted for inclusion in Robert Katz Publications by an authorized administrator of DigitalCommons@University of Nebraska - Lincoln. 
Published in Physics in Medicine and Biology 19:4 (July 1974), pp. 413-435;

doi: 10.1088/0031-9155/19/4/001 Copyright (C) 1974 Institute of Physics Publishing.

Used by permission. http://www.iop.org/EJ/journal/PMB

Submitted June 20, 1973.

\title{
Heavy Particles in Therapy: An Application of Track Theory
}

\author{
Robert Katz and S. C. Sharma \\ Behlen Laboratory of Physics, University of Nebraska-Lincoln, \\ Lincoln, Nebraska 68508, U.S.A.
}

\begin{abstract}
The survival, OER, and RBE for HeLa, leukemia, and kidney cells after irradiation with $14 \mathrm{MeV}$ neutrons, pion beams, and heavy ion beams dispersed by ridge filters are calculated. Simple beam models and the delta-ray theory of cellular survival are used in the calculations, which refer to a mixed radiation environment and the potential application of these irradiation systems in radiotherapy.
\end{abstract}

\section{Introduction}

The experience of radiotherapists has been accumulated with low LET radiations, where absorbed dose is a sufficient description of a radiation field. With high LET radiations, such as neutrons, pions, and heavy ions, the radiation field consists of a spectrum in energy and particle type, of primary and secondary heavy ions, gammarays, and light ions, the interaction of which with both tissue and dosimeters is complex. The measurement of absorbed dose alone is not adequate to predict the end point of interest, i.e., the end point is not a single valued function of dose. The application of a simple multiplicative factor, often called a "quality factor," to convert measured dose to an "effective dose" is again inadequate. Even in those cases where "quality" is "dose modifying," that is, where the shape of the dose-response curve is similar for radiations of different quality and the curves for two different radiation fields may be superimposed by a change of scale of the dose axis, the scale factor varies from detector to detector. An additional problem arises from the spatial variation of "quality," as the energy and particle spectrum vary from point to point in an irradiated volume. For high LET radiations, isodose contours are isoeffect contours only if the particle-energy spectrum remains constant. An isoeffect contour for one detector cannot be assumed to be an isoeffect contour for all detectors.

The potential advantages of these high LET radiations to radiotherapy, through improved depth dose, enhanced oxygen enhancement ratio (OER), and more nearly equal effect on cells of all ages, have been discussed elsewhere (Boone and Wiley 1971, Tobias, Lyman, and Lawrence 1972). In the present work illustrative calculations of cell survival, OER, and relative biological effectiveness (RBE) after irradiation with $14 \mathrm{MeV}$ neutrons, negative pions, and heavy ion beams are made from the 
delta-ray theory of track structure (Butts and Katz 1967, Katz, Ackerson, Homayoonfar, and Sharma 1971, Katz and Sharma 1973). While the killing of cells in vivo is a more reliable guide to the overall effects of radiation on the relevant tissue (Alper 1973) than the killing of cells in vitro, cellular radiosensitivity parameters have been evaluated only for in vitro experiments. Though the predictions of the present theory cannot be expected to be a precise guide to clinical experience, the concepts shown in these illustrations should be of interest to the radiotherapist contemplating clinical trials of these new radiation techniques.

\section{Concepts of the theory}

The details of the delta-ray theory of track structure, as applied to biological cells, are given elsewhere (Katz et al. 1971, Katz and Sharma 1973). The response of cells to ionizing radiation is summarized by four experimental parameters: $m$ and $E_{0}$, determined from the cell survival curve after $\gamma$-ray irradiation and being the extrapolation number and the "extrapolated D-37 dose" from the final slope of the survival curve; and $\sigma_{0}$ and $\kappa$, being the plateau (or saturation) cross-section and the value of $z^{2} / 4 \beta^{2}$ at which it is achieved, when cells are bombarded with heavy ion beams of different effective charge number $z$ and velocity $c=\beta c$ where $c$ is the velocity of light. From these four parameters and the functional form of the survival curve provided by the theory, it is possible confidently to predict the survival of biological cells in any specified radiation environment.

The complexity of the response of mammalian or bacterial cells to different radiation environments is expected from their response to $\gamma$-ray irradiation. If the logarithm of the surviving fraction of a cellular population is plotted against the $\gamma$-ray dose, the curve typically has an initial shoulder followed by a straight line. This shape implies an initial accumulation of sublethal damage, before the final killing event. The inactivation by the accumulation of sublethal damage over the irradiation period is named the "gamma-kill mode".

When populations of cells are irradiated by beams of particles of different charge and speed, the survival curves which result are identical with those for $\gamma$-rays if $z^{2} /$ $\kappa \beta^{2} \ll 1$ (i.e., low LET radiation). As $z^{2} / \kappa \beta^{2}$ increases, the LET increases, and the survival curves lose their shoulder as $z^{2} / \kappa \beta^{2}$ approaches 4 (i.e., at the saturation crosssection), and no shoulders occur if $z^{2} / \kappa \beta^{2} \gg 1$. The passage of one primary charged ion is sufficient to kill the cell, and this mode of killing is named "ion-kill." No accumulation of sublethal damage is needed.

Within the ion-kill mode we distinguish between two different track situations or "regimes." In the "grain-count regime," successive clusters of ions or delta-rays are formed relatively far apart along the track of the primary ion, and a cell is inactivated by the passage of the single primary ion through its nucleus. An example would be a fast charged particle of low $z$. In the "track-width regime," however, a cell may be inactivated by the cooperative energies of several relatively long-range delta-rays which pass through its nucleus even though the primary ion's path does not. An example would be a fast particle of high $z$. In both regimes of the ion-kill mode, the cell is inactivated by a single "hit" or passage of one primary ion: in its transit time of about $10^{-15} \mathrm{~s}$. There is no accumulation of damage. 
In irradiations with particles having a range of LET, the initial slope of the survival curve must be attributed to the ion-kill mode, because at low dose the primary charged particles are so far apart, on the average, that it is unlikely that their deltarays overlap in the nucleus of a cell.

In the grain-count regime, the fraction of track segments of a monoenergetic beam of particles in which the inactivation is in the ion-kill mode is

$$
P=\left[1-\exp \left(-z^{2} / \kappa \beta^{2}\right)\right]^{\mathrm{m}} \text {. }
$$

The quantity $P$ also represents the probability that a cell is inactivated by the passage of a single ion through its nucleus. It approximates the fraction of the dose deposited by the beam in the ion-kill mode. Now the total dose deposited by a beam of $F$ ions per $\mathrm{cm}^{2}$ is

$$
D=F L
$$

where $L$ is the linear energy transfer $\operatorname{LET}_{\infty}$. Therefore the dose delivered to the gamma-kill mode of inactivation, where secondary electrons from different heavy ions act on cells through the accumulation of sub-lethal damage, is

$$
D_{r}=(1-P) D
$$

From the "single-hit" nature of the ion-kill process, by contrast, we write that the probability of cell survival, $\Pi_{i^{\prime}}$ in the ion-kill mode is

$$
\Pi_{i}=\exp (-\sigma F)
$$

where $\sigma$ is the interaction cross-section of the biological target.

In the grain-count regime, the interaction cross-section $\sigma$ reaches its plateau (saturation) value, $\sigma_{0}$, approximating the cross-sectional area of the nucleus, when every cell through which an ion passes is inactivated, at $z^{2} / \kappa \beta^{2}=4$. At lower values of $z^{2} /$ $\kappa \beta^{2}$, when only a fraction $P$ of the intersected cells is inactivated, the cross-section is simply

$$
\sigma=\sigma_{0} P
$$

At values of $z^{2} / \kappa \beta^{2}$ greater than 4 , in the track width regime, $\sigma \geq \sigma_{0}$ and $P \simeq 1$.

The probability for survival in the gamma-kill mode follows the same functional form as for survival after $\gamma$-ray irradiation,

$$
\Pi_{\gamma}=1-\left[1-\exp \left(-D_{\gamma} / \mathrm{E}_{0}\right)\right]^{m} \text {. }
$$

After irradiation with a beam of particles, $N$ cells of an initial population of $N_{0}$ cells survive:

$$
N / N_{0}=\Pi_{i} \times \Pi_{\gamma}
$$

The RBE of a heavy ion irradiation is defined as the ratio of the dose of $\gamma$-rays to the dose of heavy ions which yields the same survival. The RBE is determined by the functional form of the equations above. When $z^{2} / \kappa \beta^{2} \ll 1$ (i.e., for low LET radiation), the $\mathrm{RBE}=1$, for the cells cannot distinguish between the random tangle of secondary electrons produced by $\gamma$-rays or energetic ions. When $P \simeq 1 / 2$, about half the intersected cells are inactivated by the passage of a single ion through them and about half 
the dose is delivered to the gamma-kill mode; here the RBE passes through its maximum value. This occurs at $z^{2} / \kappa \beta^{2} \simeq 1.5$, for $m=2.5$ or 3 . A further increase wastes energy by depositing it in cells already inactivated. When $z^{2} / \kappa \beta^{2} \gg 1$ (very high LET radiation), the inactivation is in the track width regime, virtually all the dose being deposited in the ion-kill mode.

Cellular radiosensitivity parameters fitted to many types of cells for which experimental data have been published are shown in Table 1. There we see that values of $m$ and $\sigma_{0}$ (extrapolation number and saturation cross-section) are identical for aerobically and anoxically irradiated cells of the same type, while $E_{0}$ and $\kappa$ (survival curve

Table 1. Cellular radiosensitivity parameters. The parameters $E_{0^{\prime}} \sigma_{0^{\prime}} m$, and $\kappa$ are fitted visually to experimental survival data after irradiation with X-rays and heavy ions, except for parameters for the anoxic irradiation of HeLa cells, which is fitted to X-ray and $14 \mathrm{MeV}$ neutron data. (See Katz et al. 1971, Katz and Sharma 1973)

\begin{tabular}{|c|c|c|c|c|c|c|c|}
\hline Material & $\begin{array}{l}\text { Source } \\
\text { of data }\end{array}$ & & $\begin{array}{c}E_{0} \times 10^{-4} \\
\left(\mathrm{erg} \mathrm{cm}^{-3}\right)\end{array}$ & $\begin{array}{c}\sigma_{0} \times 10^{9} \\
\left(\mathrm{~cm}^{2}\right)\end{array}$ & $m$ & $\kappa$ & $\begin{array}{c}\left(E_{0} \sigma_{0} / \kappa\right) \times 10^{5} \\
\left(\mathrm{erg} \mathrm{cm}^{-1}\right)\end{array}$ \\
\hline \multirow{3}{*}{$\begin{array}{c}\text { Bacterial } \\
\text { spores }\end{array}$} & \multirow[t]{3}{*}{1} & $\mathrm{~N}_{2}$ & 590 & 2.0 & 4 & 950 & 1.2 \\
\hline & & & 470 & 2.0 & 4 & 800 & 1.2 \\
\hline & & \multirow[t]{5}{*}{$\mathrm{H}_{2}^{2} \mathrm{SO}_{4}$} & 1100 & 2.0 & 4 & 1100 & 2.0 \\
\hline \multirow{2}{*}{$\begin{array}{l}\text { Diploid } \\
\text { yeast }\end{array}$} & \multirow[t]{2}{*}{2} & & 500 & 3.5 & 3 & 1600 & 1.1 \\
\hline & & & 250 & 3.5 & 3 & 1100 & 0.8 \\
\hline $\begin{array}{l}\text { Haploid } \\
\text { yeast }\end{array}$ & 3 & & 40 & 13 & 2 & 1800 & 0.3 \\
\hline $\begin{array}{l}\text { E. coli } \\
\text { wp2hcr + }\end{array}$ & 4 & & 33 & 4.8 & 2 & 800 & 0.2 \\
\hline \multirow[t]{2}{*}{ T-1 kidney } & \multirow[t]{2}{*}{5} & $\mathrm{~N}_{2}$ & 4.6 & 540 & 2.5 & 1900 & 1.3 \\
\hline & & $\mathrm{O}_{2}$ & 1.8 & 540 & 2.5 & 1400 & 0.7 \\
\hline \multirow[t]{2}{*}{ T-1 kidney } & \multirow[t]{2}{*}{6} & $\mathrm{~N}_{2}^{2}$ & $4.6^{*}$ & 670 & 2.5 & 1300 & 2.4 \\
\hline & & $\mathrm{O}_{2}^{2}$ & 1.7 & 670 & 2.5 & 1000 & 1.1 \\
\hline \multirow{2}{*}{$\begin{array}{l}\text { Leukemia } \\
\text { p-388 }\end{array}$} & \multirow[t]{2}{*}{7} & $\mathrm{~N}_{2}^{2}$ & 3.5 & 580 & 2.5 & 2100 & 1.0 \\
\hline & & $\mathrm{O}_{2}^{2}$ & 1.5 & 580 & 2.5 & 1750 & 0.5 \\
\hline Hamster & 8 & & 1.9 & $460^{* *}$ & 2.5 & 1400 & 0.6 \\
\hline \multirow[t]{2}{*}{ HeLa } & 9 & $\mathrm{~N}_{2}$ & 3.7 & 560 & 3 & 1100 & 1.9 \\
\hline & 10 & $\mathrm{O}_{2}$ & 1.4 & 560 & 3 & 750 & 1.0 \\
\hline
\end{tabular}

Re-evaluated: * from 2.9, ** from 500.

Sources:

1. Powers, E. L., Lyman, J. T., and Tobias, C. A., 1968, Int. J. Radiat. Biol., 14, 313.

2. Mortimer, R., Brustad, T., and Cormack, D. V., 1965, Radiat. Res., 26, 465.

3. Sayeg, J. A., Birge, A. C., Beam, C. A., and Tobias, C. A., 1959, Radiat. Res., 10, 449.

4. Munson, R. J., Neary, G. J., Bridges, B. A., and Preston, R. J., 1967, Int. J. Radiat. Biol., 13, 205.

5. Barendsen, G. W., Koot, C. J., Van Kersen, G. R., Bewley, D. K., Field, S. B., and Parnell C. J., 1966, Int. J. Radiat. Biol., 10, 317.

6. Todd, P., 1967, Radiat. Res. Suppl., 7, 196.

7. Berry, R. J., 1970, Radiat. Res., 44, 237.

8. Skarsgard, L. D., Kihlman, B. A., Parker, I., Pujara, C. M., and Richardson, S., 1967, Radiat. Res. Suppl., 7, 208.

9. Nias, A. H. W., Greene, D., Fox, M., and Thomas, R. L.,1967, Int. J. Radiat. Biol., 13, 449.

10. Deering, R. A., and Rice, Jr., R., 1962, Radiat. Res., 17, 774. 
slope and value of $z^{2} / \kappa \beta^{2}$ at which saturation is achieved) are different. The fitting of the parameters to experimental data has been done by eye. An attempt to assign uncertainties to the values of the parameters is now under way, but this is made difficult by the reluctance of the original investigators to assign uncertainties to either survival or dose measurements. No explanation is now offered for the relationships of the anoxic and aerobic parameters. Nevertheless, they enable us to associate the oxygen effect with the fraction of the dose, $D \gamma / D$, delivered to the gamma-kill mode. We therefore expect that the OER, of the dose at constant survival for anoxic and aerobic irradiations of the same cell type, will follow the gamma-kill dose fraction as $z^{2}$ / $\kappa \beta^{2}$ varies for different irradiations.

This overall description of the response of biological cells to energetic heavy ions follows from the identification of two inactivation modes and two track regimes. The functional form of the present theory for cell survival is an extension of the theory of particle tracks in emulsion which is published elsewhere (Katz and Kobetich 1969). Changes in OER and RBE with $z^{2} / \beta^{2}$ arise from the relative size and shape of the detector (or biological target) with respect to the spatial and temporal distribution of secondary electrons. We do not usually know the number of classes of cellular sensitive elements, the number of elements in each class, their radiosensitivity, their spatial distribution within the cell, or the ways in which they interact to yield the observed endpoint. Until some of these questions are clarified, it is not likely that a detailed understanding of cellular radiosensitivity parameters will be achieved from first principles. At present levels of understanding we are fortunate to be able to achieve a macroscopic or average description as in the present work.

The response of cells to a mixed radiation environment can be calculated by applying the preceding equations, segment by segment of $z^{2} / \beta^{2}$, to each particle track, to find the ion-kill survival probability and the gamma-kill dose contribution in each segment. The product of these ion-kill survival probabilities is the ion-kill survival probability of the total radiation field. The sum of the gamma-kill dose contributions is the total gamma-kill dose, whose value yields the gamma-kill survival probability. The product of these two survival probabilities yields the surviving fraction, as in equation (7).

So long as the quantities $\Pi_{i^{\prime}} \Pi_{\gamma^{\prime}}$ and $D$ (total dose) are the same for two radiation fields, the fields are equivalent irradiations (Katz, Sharma, and Homayoonfar 1972): the plots of cell survival as a function of dose are congruent, for a particular cell in a particular radiation field. In some cases the survival curves achieved with neutron and pion irradiations may be simulated by track segment irradiations with accelerated lithium ions. This suggests that a measurement of the gamma-kill dose fraction for an appropriate simulation of the environment-cell combination can be applied to the theory to predict the cell survival curve, the RBE, and the OER for a known radiation environment. Work is in process to attempt to specify the nature of the detector combination (e.g., silicon and Fricke dosimeters) which can achieve such a result. The needed quantities can be calculated from the theory if the spectral composition of the radiation field has been measured, but one might hope that simpler physical measurements will suffice. 


\section{Cell survival in mixed radiation environments}

In order to apply the theory, we need to know the spectral composition of the radiation field. The secondary particle spectrum from the irradiation of tissue with 14 $\mathrm{MeV}$ neutrons is available from the work of Caswell and Coyne (1972). The spectrum for the capture of negative pions is calculated by Guthrie, Alsmiller, and Bertini (1968). Turner, Dutrannois, Wright, Hamm, Baarli, Sullivan, Berger, and Selzter (1972) analyze the depth dose in water, from the pion beam of the $600 \mathrm{MeV}$ SynchroCyclotron at CERN, into a "star dose" and "fast pion track dose", and make it possible to estimate cell survival as a function of depth in this beam. In this case the dose contribution from the fast pion track is taken to be all gamma-kill dose, while the star dose is apportioned to gamma-kill and ion-kill according to the secondary particle spectrum given by Guthrie et al. (1968).

A beam of heavy charged particles can be approximated by a simple model incorporating attenuation and straggling, but neglecting secondary particle production, beam contamination, energy inhomogeneity, and focusing. Attenuation is based on an interaction cross-section calculated from the RMS value of the beam and target nuclear radii, applied to a medium which has the nuclear composition of tissue and the stopping power of water. The influence of straggling on the variation of the energy spectrum of beam particles as a function of depth is found by taking an initially monoenergetic beam to be made up of fractions having different velocity-stopping power relationships. Both the intensity in the several fractions and the stopping power relationships are constructed so as to yield the straggling Gaussian (Evans 1955). In this way a reasonable approximation to the velocity spectrum of particles in and near the Bragg peak is achieved. The neglect of secondary particles becomes increasingly important as both the energy and the atomic number of the beam ions are increased. Since secondary particles are of lower $Z$ than primaries, have nominally the same average velocity and are projected mainly in the forward direction, their effect is (1) to increase the dose, (2) to decrease the sharpness of the Bragg peak as calculated, and (3) to dilute the high LET effect of the primary beam so as to increase the gamma-kill dose fraction, with an accompanying reduction in RBE and an increase in the OER.

Calculated survival curves for kidney, leukemia, and HeLa cells exposed to 14 $\mathrm{MeV}$ neutrons, from the parameters of Table 1, are compared to experimental data (Barendsen and Broerse 1966, 1968; Nias, Greene, Fox, and Thomas 1967; Berry, private communication) in Figures 1-3. In all cases, except for the anoxic irradiation of HeLa cells with neutrons, the cell survival parameters were obtained independently of the neutron data. The only available data for the anoxic irradiation of HeLa cells is from $\gamma$-ray and neutron irradiation, so that the neutron data are used to adjust these parameters for HeLa cells only.

Calculated survival curves for human kidney cells (using parameters obtained by fitting the survival data of Todd 1966), after exposure to $10 \mathrm{MeV}$ protons, $14 \mathrm{MeV}$ neutrons, and the secondary particle spectrum from stopped negative pions, are shown in Figure 4. Similar curves are found for all the cells of Table 1. Typically the pion curve lies between the curves for protons and $14 \mathrm{MeV}$ neutrons. Values of the 


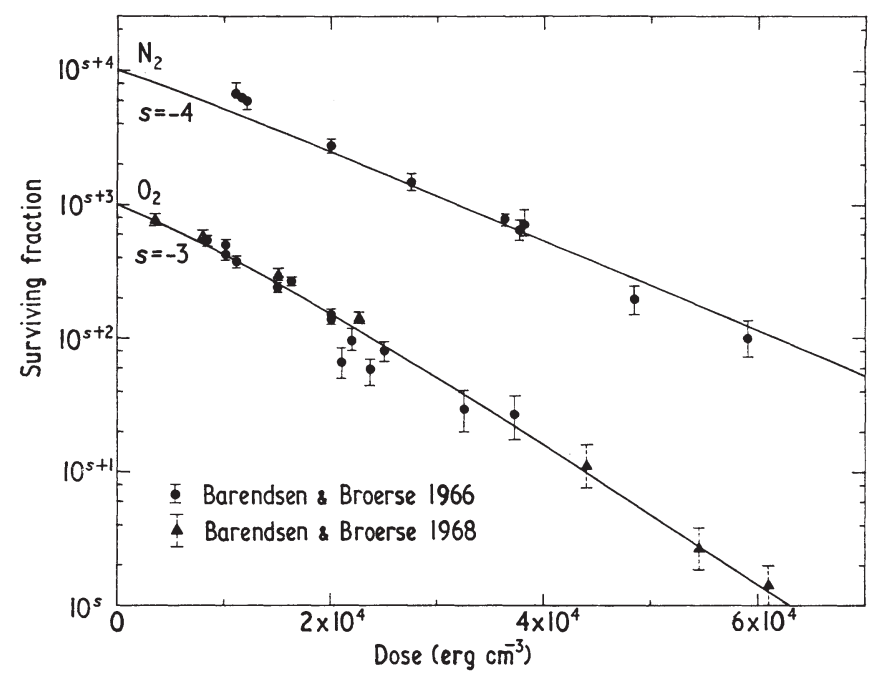

Figure 1. Calculated survival of T-1 kidney cells irradiated with $14 \mathrm{MeV}$ neutrons (from parameters fitted to the heavy ion data of Todd (1966)) are compared to experimental survival data of Barendsen and Broerse $(1966,1968)$.

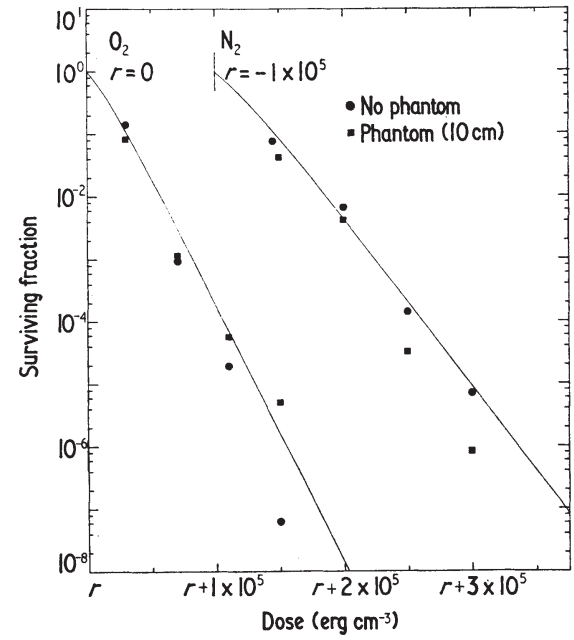

Figure 2. Calculated survival of leukemia cells irradiated with $14 \mathrm{MeV}$ neutrons as compared to experimental survival data (Berry, private communication).

OER and RBE for these irradiations are shown in Table 2, with the RBE for $10 \mathrm{MeV}$ proton irradiations taken as unity. Values from Table 2 of the OER and RBE (aerobic) of 1.6 and 2.0 respectively, for the irradiation of kidney cells with the secondary products from stopped negative pions in tissue, may be compared with experimental values obtained by Raju, Gnanapurani, Richman, Martins, and Barendsen (1972), of 1.5 and 2.4, in the peak of the depth dose distribution of the negative pion irradiation facility of the 184 inch cyclotron. 


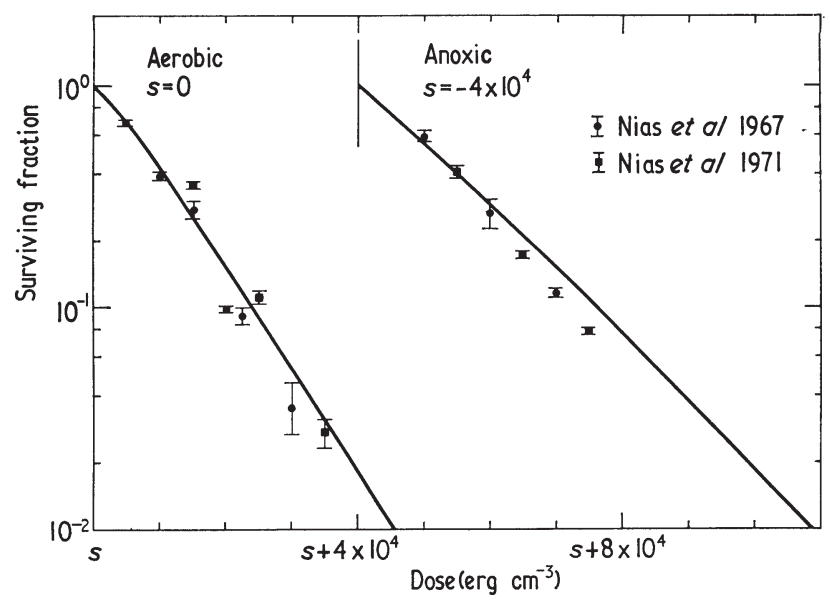

Figure 3. Calculated survival of HeLa cells irradiated with $14 \mathrm{MeV}$ neutrons, as compared to experimental survival data (Nias et al. 1967). In this case the survival data for the anoxic irradiation of HeLa cells with $14 \mathrm{MeV}$ neutrons is part of the input data from which the cell survival parameters are established.

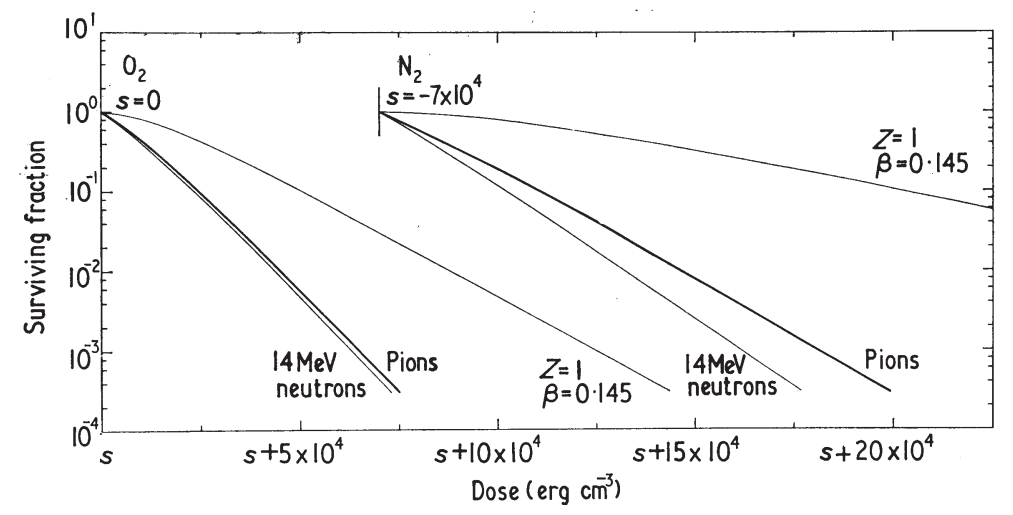

Figure 4. Calculated survival curves for T-1 human kidney cells after exposure to $10 \mathrm{MeV}$ protons, $14 \mathrm{MeV}$ neutrons, and stopped negative pions, both anoxically and aerobically.

In its present form, dose rate effects are not incorporated into the theory, although currently available pion beams are of low intensity. In calculating the effects to be expected from pion irradiation, the dose is assumed to be delivered in a time short compared to cellular repair time. Recent analyses of the depth dose curves in water from the CERN pion beam (Turner et al. 1972) imply that it is composed of $63 \%$ negative pions, $14 \%$ negative muons and $23 \%$ electrons, and have separated the depth-dose curves of a beam of initial momentum $176 \mathrm{MeV} / c$ into a component due to pion stars and a second component due to the normal electronic stopping power of the pions and other particles due to their slowing. In the absence of more detailed knowledge 
Table 2. Calculated values of the RBE and OER at $10 \%$ survival for irradiation of the cells of Table 1 with $10 \mathrm{MeV}$ protons, $14 \mathrm{MeV}$ neutrons and "stopped negative pions"

\begin{tabular}{lcccccc}
\hline & & $\begin{array}{c}10 \mathrm{MeV} \text { protons } \\
\text { OER }\end{array}$ & \multicolumn{2}{c}{$14 \mathrm{MeV}$ neutrons } & \multicolumn{2}{c}{ Stopped pions } \\
& & RBE & OER & RBE & OER \\
\hline \multirow{2}{*}{ Bacterial spores } & $\mathrm{N}_{2}$ & 1.3 & 2.0 & 1.2 & 1.7 & 1.2 \\
& $\mathrm{O}_{2}$ & & 1.8 & & 1.7 & \\
Diploid yeast & $\mathrm{N}_{2}$ & 2.2 & 2.7 & 1.4 & 1.6 & 2.0 \\
& $\mathrm{O}_{2}$ & & 1.8 & & 1.5 & \\
Haploid yeast & & & 1.2 & & 1.2 & \\
T-1 kidney cells & $\mathrm{N}_{2}$ & 2.6 & 4.1 & 1.4 & 3.3 & 1.6 \\
& $\mathrm{O}_{2}$ & & 2.1 & & 2.0 & \\
Leukemia p-388 & $\mathrm{N}_{2}$ & 2.3 & 2.4 & 1.5 & 1.8 & 1.8 \\
& $\mathrm{O}_{2}$ & & 1.5 & & 1.4 & \\
Hamster & & & 1.6 & & 1.5 & \\
HeLa & $\mathrm{N}_{2}$ & 2.8 & 3.5 & 1.5 & 2.6 & 1.9 \\
& $\mathrm{O}_{2}$ & & 1.9 & & 1.8 & \\
\hline
\end{tabular}

RBE $=$ Dose at $10 \%$ survival (X-rays)/ dose at $10 \%$ survival (14 MeV neutrons or pions).

OER $=$ Dose at $10 \%$ survival (anoxic) $/$ dose at $10 \%$ survival (aerobic) .

of the beam, a preliminary calculation of cellular inactivation in this beam has been made, finding the ion-kill survival probability from the pion stars, and adding the gamma-kill dose from the pion stars to the normal electronic stopping power component of the dose. From this procedure we calculate the survival of kidney cells at the dose peak of the CERN pion beam, and compare it with a survival curve calculated for stopped pions, and with survival data measured by Raju et al. (1972) in the Bragg peak of the Berkeley pion beam, whose contamination is similar to that of the CERN beam, as shown in Figure 5. A Monte Carlo calculation, by Armstrong (private communication) yields a pion survival curve nearly midway between these two curves. In Figure 6 the total dose, the star dose (per particle), the OER, and the RBE at 10\% survival are shown as a function of depth in this beam, for kidney cells. Also shown are the survival of anoxically and aerobically irradiated kidney cells as a function of depth in this beam, for a fluence at which $30 \%$ of aerobically irradiated cells survive in the region of maximum effectiveness.

For this beam are also calculated the surviving fraction of aerobically and anoxically irradiated HeLa; kidney and leukemia cells, at entrance, at a depth of $20 \mathrm{~cm}$ where the survival is minimal, and at a depth of $22.5 \mathrm{~cm}$ where the OER is minimal. These results are shown in Table 3. Also given are the ratios of survival of anoxically to aerobically irradiated cells (AAR); these ratios indicate the effectiveness of the radiation in killing hypoxic cells. 


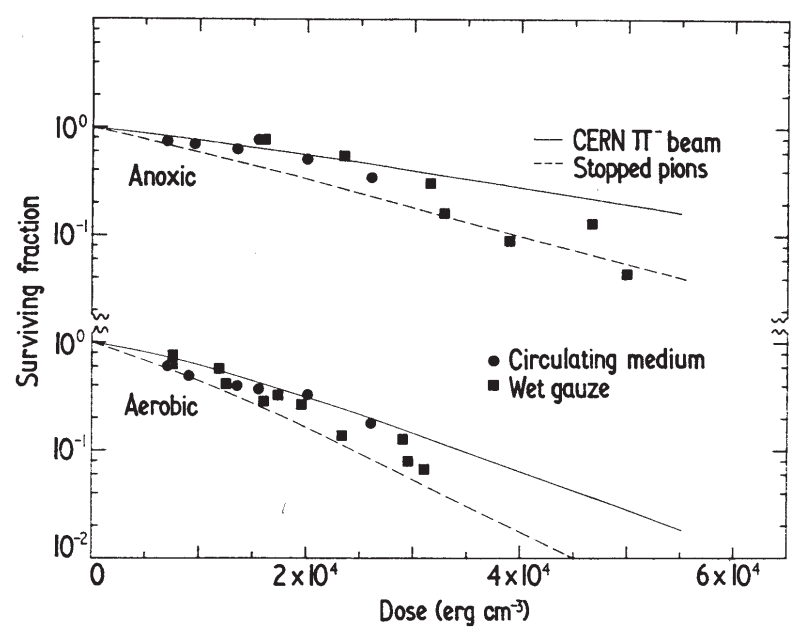

Figure 5. Data of Raju et al. (1972) for the survival of kidney cells in the dose peak of the Berkeley pion beam are compared to survival curves calculated for stopped pions (dashed lines) and for the dose peak of the CERN beam (solid line).

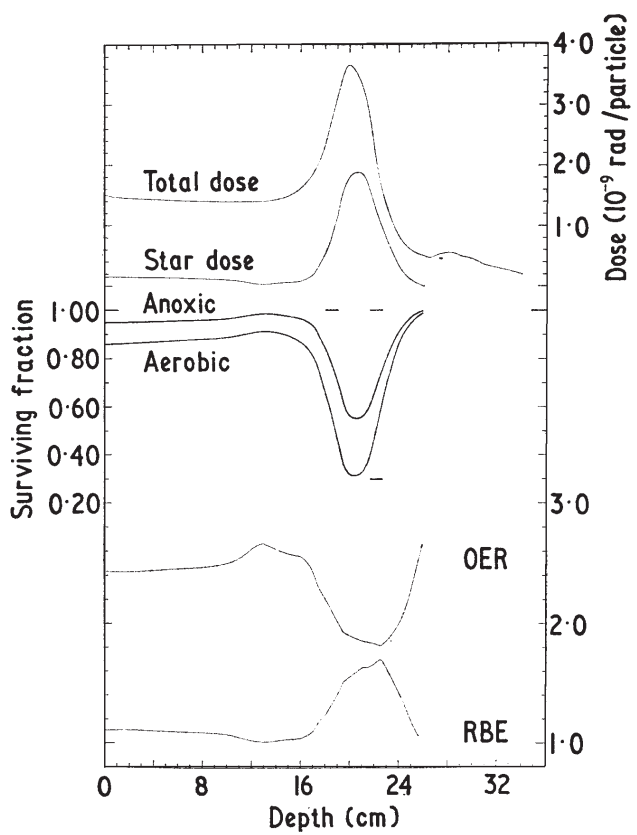

Figure 6. The decomposition of the CERN negative pion beam (Turner et al. 1972) into dose contributions from stars and from other aspects of the beam (principally normal stopping power contributions) has made it possible to approximate the response of kidney cells to the pion beam, as in Figure 5. For this calculation the star dose is assumed to behave like stopped pions in tissue, while the remainder of the dose is taken to contribute only to the gamma-kill mode. Shown are the total dose, the star dose, the survival of anoxically and aerobically irradiated kidney cells at a fluence of $5.5 \times 10^{10}$ particles per $\mathrm{cm}^{2}$ at which $30 \%$ of the aerobically irradiated cells survive in the region of minimum survival, and the OER and RBE as a function of depth, calculated at $10 \%$ survival. 


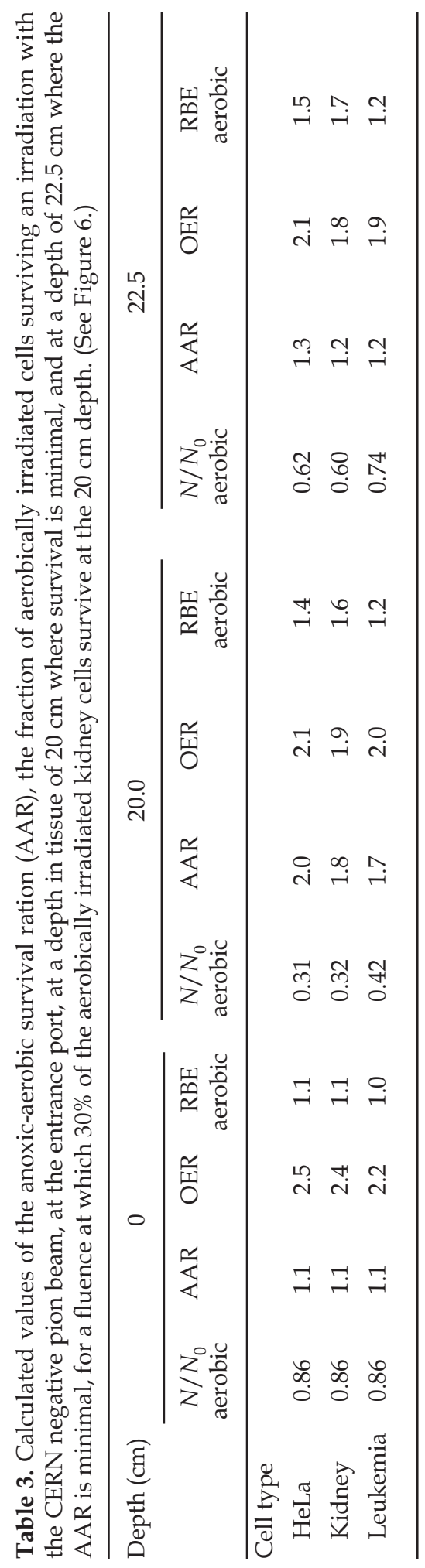




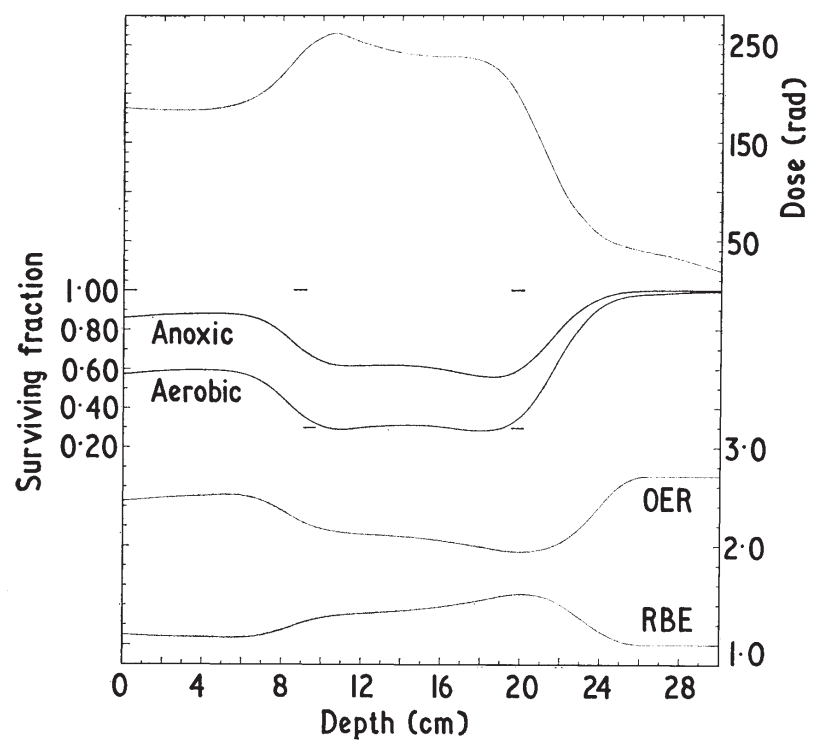

Figure 7. The dose and survival as a function of depth of kidney cells irradiated with a beam of pions dispersed to give an isosurvival region $10 \mathrm{~cm}$ wide in the tumor region. Also shown are the RBE and OER to be expected with such a beam. Single port irradiation.

When this beam is spread by a ridge filter, or otherwise dispersed in initial energy, to cover a tumor 5-10 cm thick, we must expect the gamma-kill dose fraction, and consequently the OER, to increase. To estimate the effect of a dispersed beam of negative pions, the CERN beam has been considered as displaced, modulated in intensity, and overlaid so as to yield an isosurvival region about $10 \mathrm{~cm}$ wide. In Figure 7 we show the dose and survival of aerobically and anoxically irradiated kidney cells at a fluence at which there is 30\% survival of the aerobically irradiated cells. Also shown are the RBE and OER, all as a function of depth. The same quantities are displayed for a dual port irradiation in Figure 8.

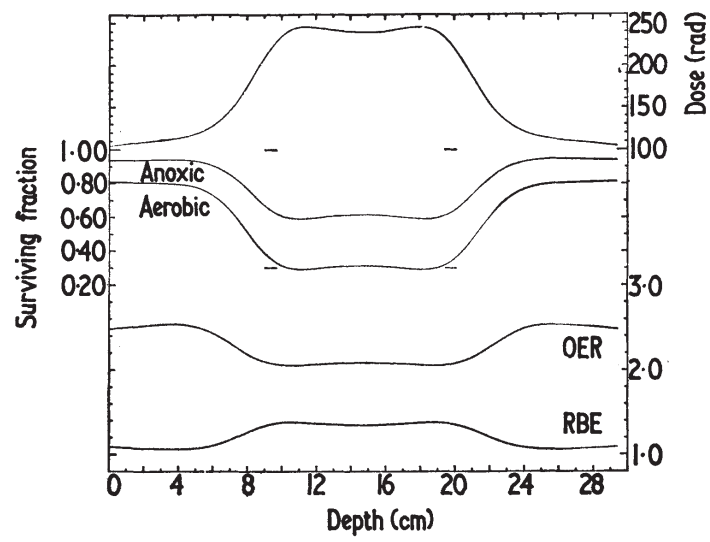

Figure 8. See caption to Figure 7. Double port irradiation. 


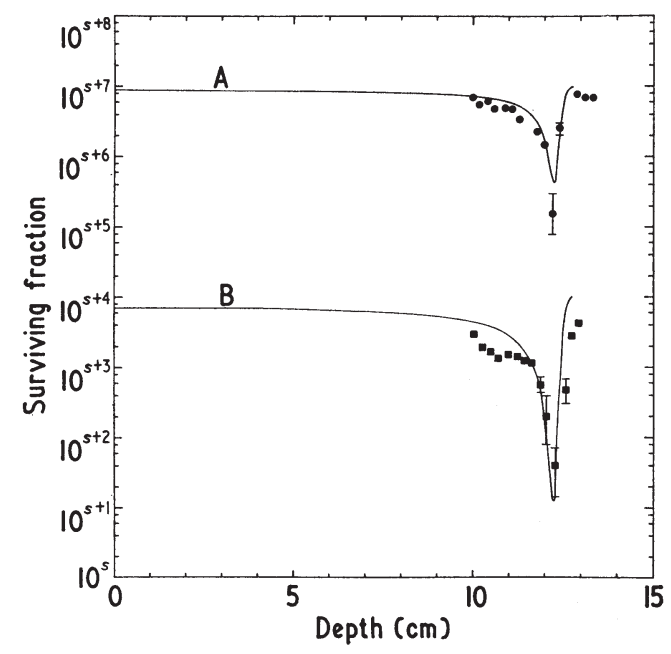

Figure 9. Calculated (solid line) survival of aerobically irradiated kidney cells as a function of depth, in a $3.9 \mathrm{GeV}$ nitrogen beam, as compared with experimental data (squares and circles) from the Princeton Particle Accelerator (Todd et al. 1971),obtained with hamster cells said to have similar radiation response to kidney cells. Data for the two curves: A, $s=-7$, fluence (ions cm${ }^{-2}$ ) $2.2 \times 10^{7} ; \mathrm{B}, \mathrm{s}$

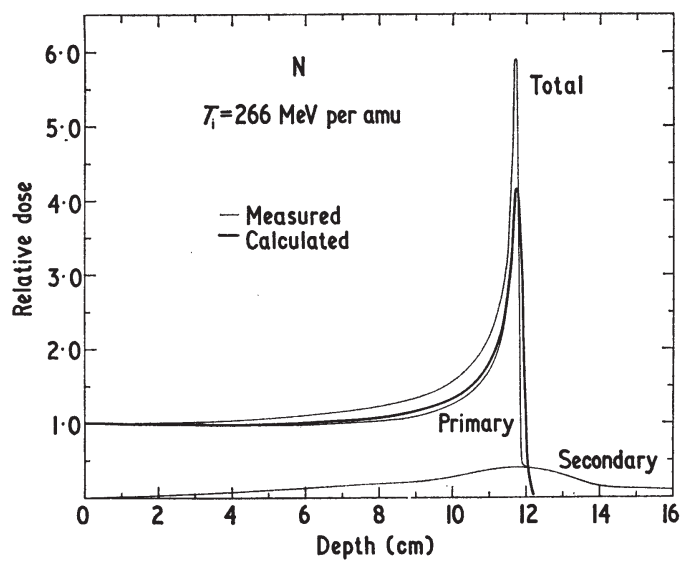

Figure 10. Calculated value (heavy line) of the relative dose from the primary beam of a $266 \mathrm{MeV}$ per amu nitrogen beam, as compared to measured value (light lines) of the total and secondary particle dose, from which an experimental value of the primary dose is inferred (Lyman et al. unpublished).

Use of the heavy ion beam model yields curves of cell survival as a function of depth in a $3.9 \mathrm{GeV}$ nitrogen beam, shown in Figure 9. For these calculations kidney cell parameters were used. The calculated results are compared to experimental survival data obtained at the Princeton Particle Accelerator with hamster cells, said to have similar radiosensitivity to kidney cells (Todd, Schroy, Vosburgh, and Schimmerling 1971). Other available data are from bombardment with a beam of nitrogen ions at $266 \mathrm{MeV}$ per amu at Berkeley (Lyman, Howard, Maccabbee, Raju, Sperinde, Walton, Welch, and Tobias, unpublished). The calculated value of the dose as a function of depth (heavy lines) compares well with the measured primary dose, as shown in Figure 10. Calculated survival curves for anoxically and aerobically irradiated kid- 


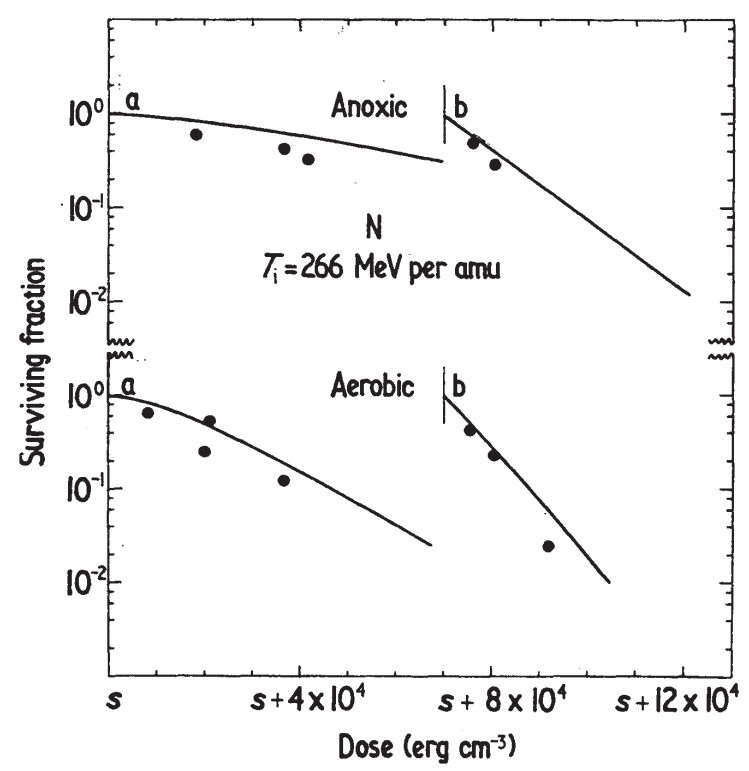

Figure 11. Calculated survival of kidney cells irradiated at two positions in the beam of Figure 10, as compared to experimental survival data of Martins et al. (unpublished). Data for the two curves: a, depth $(\mathrm{cm})=0.0, s=0 ; \mathrm{b}$, depth $(\mathrm{cm})=11.7, s=-7 \times 10^{4}$.

ney cells at two depths in the beam are shown in Figure 11 for comparison with experimental data (Martins, Roisman, Raju, and Tobias, unpublished).

Since the dose peak region in a heavy ion beam is too thin to yield uniform irradiation of tumors, the initial energy of the beam must be dispersed by some means, such as varying the beam energy, or by using a ridge filter. The latter procedure has been used by Raju, Gnanapurani, Martins, Howard, and Lyman (1972), who employed a seven step ridge filter made of heavy metal to disperse a $910 \mathrm{MeV}$ He beam, in order to obtain an isodose region several centimeters wide. For purposes of calculation this filter was simulated by a seven step filter having the composition of tissue and the stopping properties of water, to yield the results shown in Figure 12. The experimental depth dose curve of Raju et al. (1972) is shown in the upper panel in dashed lines, while the calculated depth dose curve is shown in solid lines. In the bottom panels are shown the calculated values of the OER and RBE as a function of depth, for irradiated kidney cells. In the center region, we show the survival of anoxically and aerobically irradiated kidney cells, at a fluence where $30 \%$ of the aerobically irradiated cells survive in the "tumor" region.

In Figure 13 are shown calculated survival curves for both anoxically and aerobically irradiated kidney cells, at three positions in the beam, in comparison with the experimental data. Because of the rapid fluctuations of beam quality at a depth of about $10.5 \mathrm{~cm}$, calculations were made at three adjacent depths (which may be compared to Figure 12) to span the possible range of experimental survival curves, for which the precise positioning was uncertain. 


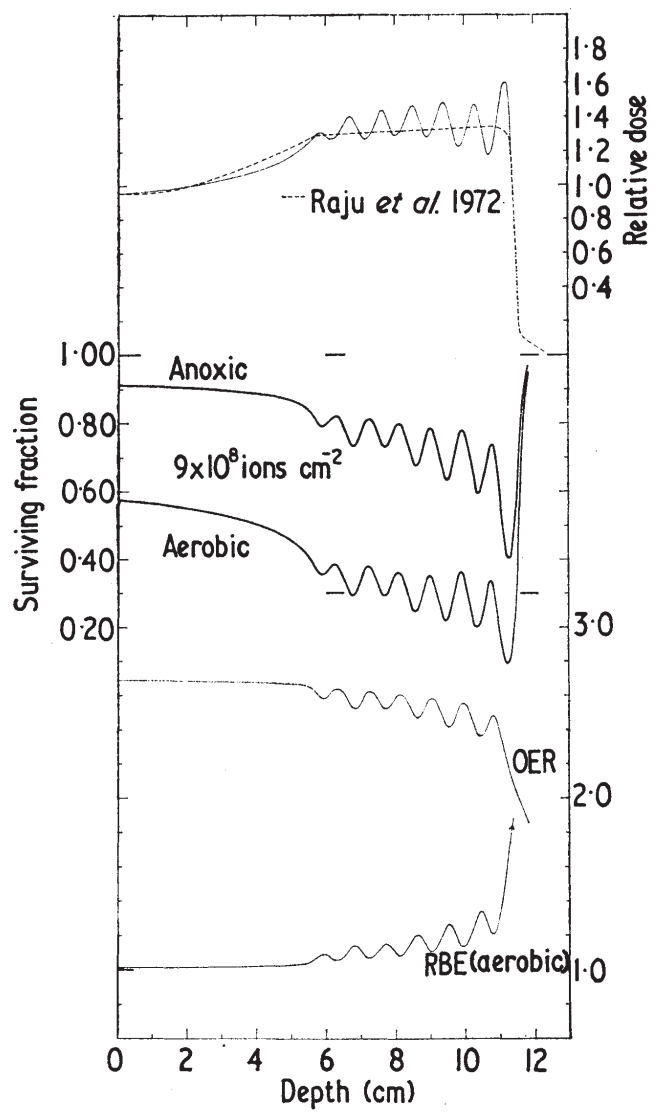

Figure 12. In an experiment to investigate the effect of spreading a $910 \mathrm{MeV}$ beam of He ions with a seven step ridge filter, the dose and survival of kidney cells was measured as a function of depth (Raju et al. 1972). Experimental depth-dose measurements are shown in dashed lines in the top panel, in comparison with a calculated curve based on a tissue-equivalent ridge filter designed to simulate the heavy metal filter used experimentally. Also shown are the survival of kidney cells irradiated anoxically and aerobically at a fluence of $9 \times 10^{8}$ ions $\mathrm{cm}^{-2}$, the RBE, and OER at $10 \%$ survival, all as a function of the depth in tissue. In the following table, the calculated values of the RBE relative to the surface and the OER at various positions in the beam are compared with the experimental values.

\begin{tabular}{ccccccc} 
& Depth & \multicolumn{2}{c}{ RBE (aerobic) } & & \multicolumn{2}{c}{ OER } \\
Position & $(\mathrm{cm})$ & Theor. & Exp. & & Theor. & Exp. \\
\hline $\mathrm{a}$ & 0.0 & 1.0 & 1.0 & & 2.7 & 2.5 \\
$\mathrm{~b}$ & 5.8 & 1.1 & 1.3 & & 2.6 & 1.8 \\
$\mathrm{c}$ & 11.1 & 1.4 & & & 2.3 & \\
$\mathrm{~d}$ & 10.5 & 1.3 & 1.4 & & 2.4 & 1.7 \\
$\mathrm{e}$ & 10.8 & 1.2 & & & 2.5 & \\
\hline
\end{tabular}




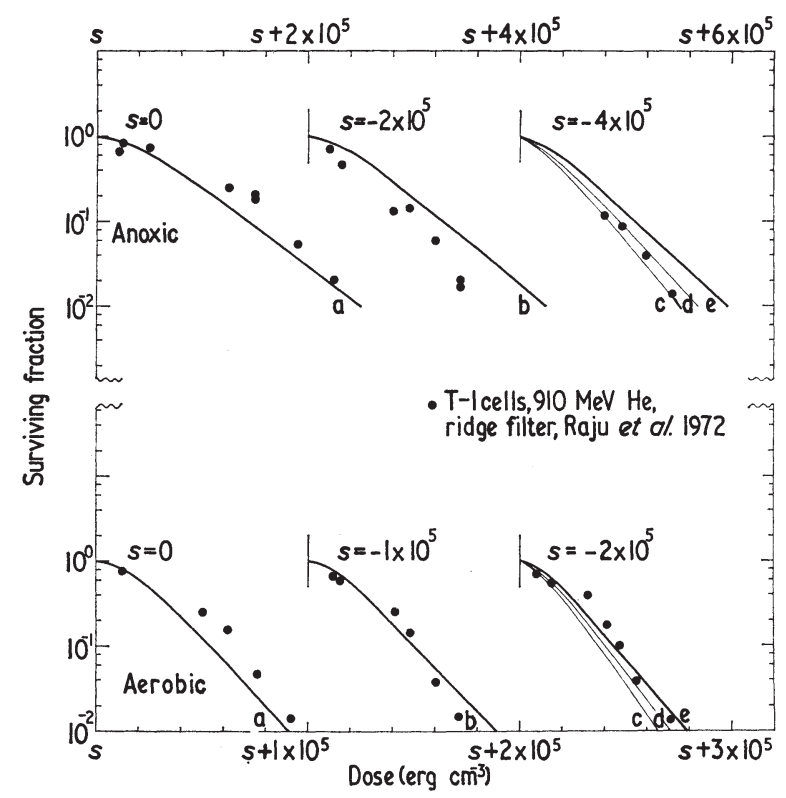

Figure 13. Survival of kidney cells in three positions in the beam of Figure 12, as compared with calculated survival curves. Because of the structure of the beam quality near the edge of the beam (at about $10.5 \mathrm{~cm}$ ), calculations are made at three adjacent positions for comparison with experimental data.

\begin{tabular}{lcrrrr} 
& $\mathrm{a}$ & $\mathrm{b}$ & $\mathrm{c}$ & $\mathrm{d}$ & $\mathrm{e}$ \\
\hline Depth (cm) & 0.0 & 5.8 & 11.1 & 10.5 & 10.8 \\
RBE (aerobic) & 1.0 & 1.1 & 1.4 & 1.3 & 1.2 \\
OER & 2.7 & 2.6 & 2.3 & 2.4 & 2.5 \\
\hline
\end{tabular}

\section{Heavy ion therapy : preclinical radiobiological calculations}

The most extensive experience of high LET radiotherapy is from the use of the MRC cyclotron's fast neutron beam at Hammersmith Hospital, so this experience is used as a starting point. In their clinical investigations of neutron irradiations, Catterall, Rogers, Thomlinson, and Field (1971) concluded that 1440 rad of fast neutrons, or $4200 \mathrm{rad}$ of orthovoltage X-rays, delivered in 12 fractions (three per week) over 25 days, caused a skin reaction within acceptable limits, and led to early response of the irradiated tumors. Since these irradiations imply that the survival of kidney or leukemia cells so irradiated lies between 25 and $40 \%$ per dose fraction, we take it to be a clinical constraint that the dose delivered in a single fraction to a tumor is one for which there would be, say, 30\% survival of aerobically irradiated kidney cells within the tumor volume, and that if this dose is repeated according to this (Hammersmith Hospital) schedule, there will be an acceptable reaction of normal tissue in the tumor region and, from the Hammersmith experience, a satisfactory early response of 
some of the tumors. The relative merit of different radiation techniques may then be based on the damage to normal tissue en route to the tumor region (as represented by the survival of aerobically irradiated cells), and on the survival of anoxically irradiated kidney cells in the tumor region, as an indication of the possibility that oxygendeprived tumor cells may survive the irradiation schedule. Emphasis is here placed on kidney cells because the parameters are better established and tested than those for leukemia and HeLa cells, though there is no reason to believe that kidney cells in culture are a better model of the response of either normal or diseased tissue. For this reason the calculations for kidney cells have been repeated for both leukemia and HeLa cells, using the parameters of Table 1, as an indication of the potential range of the results of charged particle irradiations.

To particularize the calculations, a ridge filter for heavy ion beams has been designed to yield isosurvival regions (for aerobically irradiated kidney cells) $10 \mathrm{~cm}$ wide, centered at a depth of about $12.6 \mathrm{~cm}$ in a tissue phantom, when irradiated with neon beams of appropriate energy. Calculations are made of the survival of HeLa, kidney, and leukemia cells neglecting secondary particle production, for $\mathrm{D}, \mathrm{He}, \mathrm{O}$, and Ke beams, in single and opposed port irradiations, at a fluence at which 30\% of aerobically irradiated kidney cells survive in the tumor region. The transmissions and step thicknesses of ridge filters having the composition of tissue and the stopping power of water are given in Table 4. Numerical values of the fractional survival of aerobically irradiated cells, the anoxic/aerobic survival ratio at this fluence (AAR), the OER and RBE at 10\% survival, and the dose of X-rays at which the indicated survival of aerobically irradiated cells would be obtained, are given for all three cell types in Table 5, for the entrance port and at the tumor center. Here also are given these values obtained with the spread pion beam, at "entrance" and at the center of the tumor region.

In Figures 14-17 are given the results obtained with $\mathrm{He}$ and Ne irradiations of kidney cells, for single and opposed port irradiations. In each case the energy and fluence are given, as well as the dose and the survival of anoxically and aerobically ir-

Table 4. Ridge filter having the stopping power of water and the atomic composition of tissue, designed for producing an isosurvival region of about $10 \mathrm{~cm}$ width when kidney cells are irradiated with energetic neon beams.

\begin{tabular}{ccrrrrrrr}
\hline $\begin{array}{c}\text { Fractional } \\
\text { transmission }\end{array}$ & \multicolumn{7}{c}{ Step thicknesses $(\mathrm{cm})$} \\
\hline 0.041 & 0.2 & 0.4 & 0.6 & 0.8 & 1.0 & 1.2 & 1.4 & 1.6 \\
0.024 & 1.8 & 2.0 & 2.2 & 2.4 & 2.6 & 2.8 & 3.0 & 3.2 \\
0.018 & 3.4 & 3.6 & 3.8 & 4.0 & 4.2 & 4.4 & 4.6 & 4.8 \\
0.013 & 5.0 & 5.2 & 5.4 & 5.6 & 5.8 & 6.0 & 6.2 & 6.4 \\
0.011 & 6.6 & 6.8 & 7.0 & 7.2 & 7.4 & 7.6 & 7.8 & 8.0 \\
0.009 & 8.2 & 8.4 & 8.6 & 8.8 & 9.0 & 9.2 & 9.4 & 9.6 \\
0.008 & 9.8 & 10.0 & 10.2 & 10.4 & 10.6 & 10.8 & 11.0 & 11.2 \\
\hline
\end{tabular}




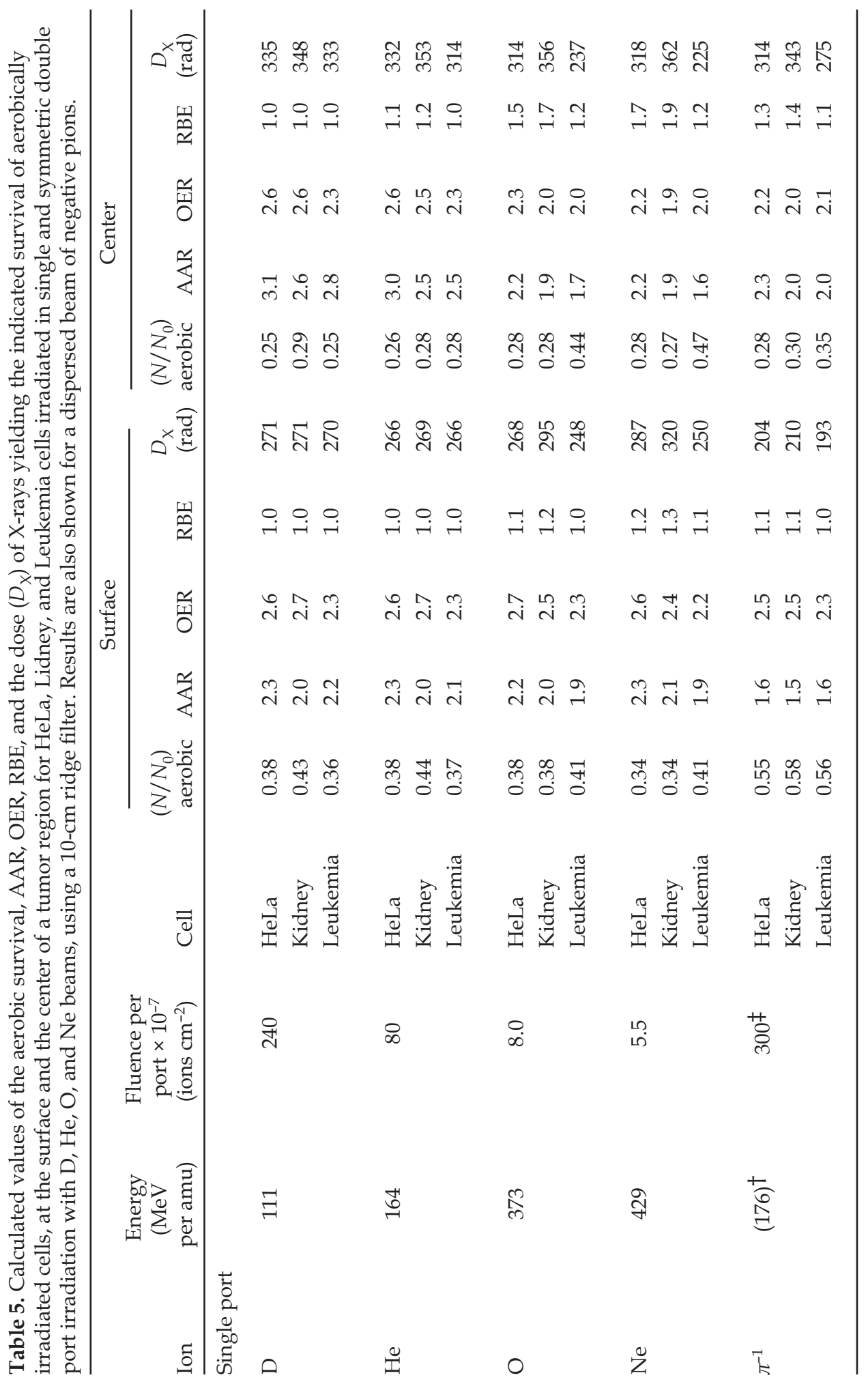




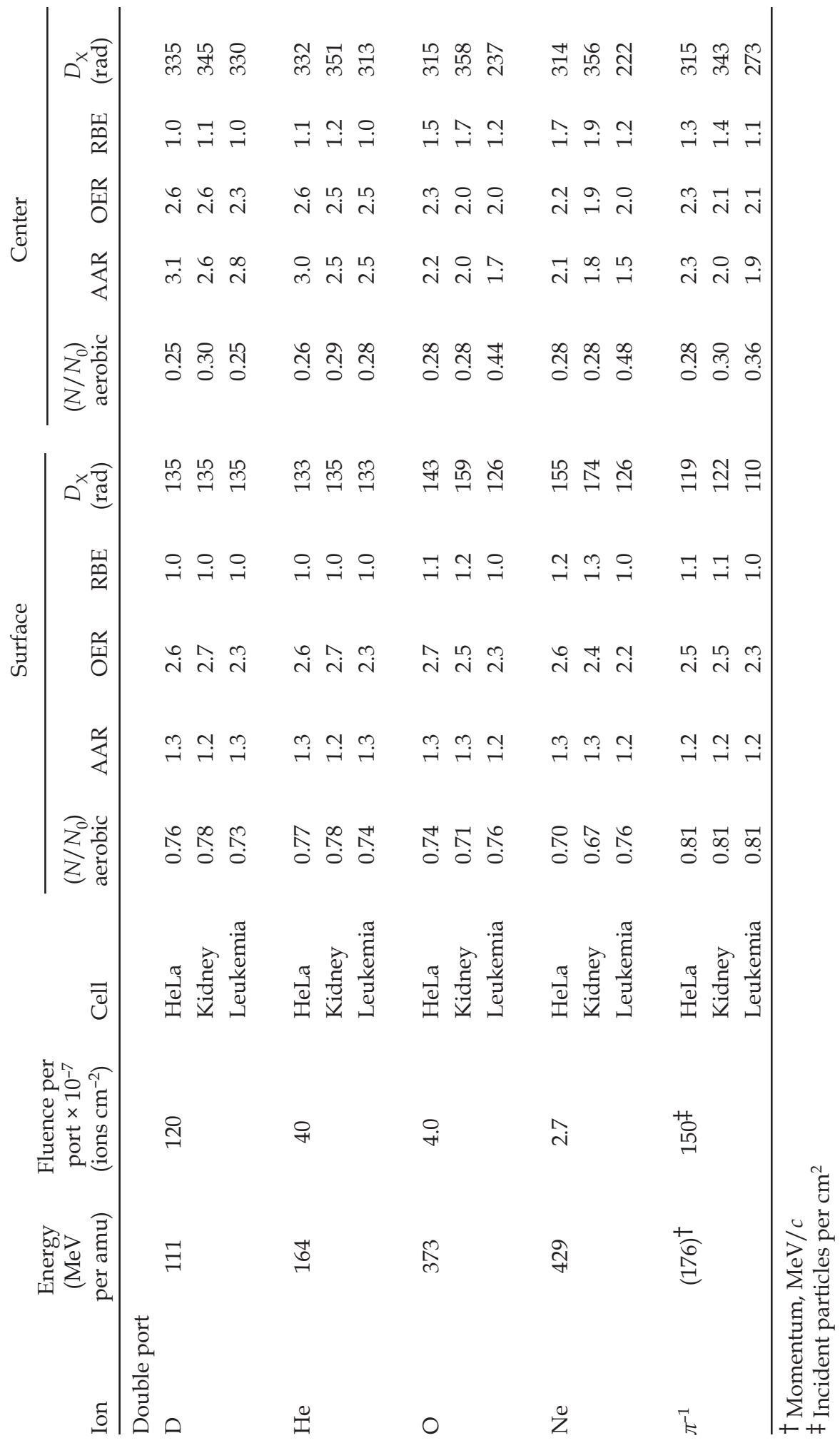




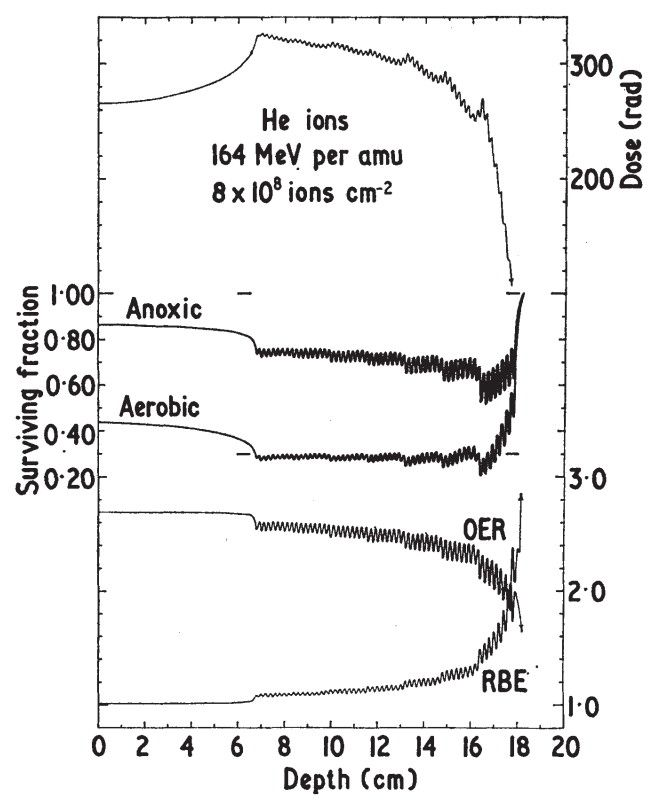

Figure 14. Calculated values of the dose as a function of depth, the survival of anoxically and aerobically irradiated kidney cells at a fluence where the survival of aerobically irradiated cells in the minimal survival region is about $30 \%$, the OER and the RBE (of aerobically irradiated cells), at $10 \%$ survival, are shown for He ions dispersed through a $10 \mathrm{~cm}$ ridge filter. Single port.

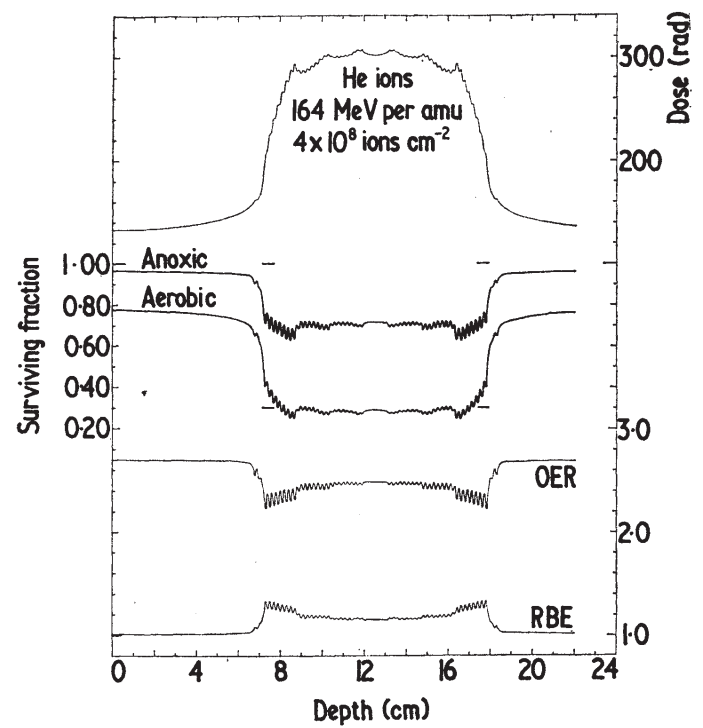

Figure 15. He ions, $10 \mathrm{~cm}$ ridge filter, double port.

radiated cells at this fluence as a function of depth. Also shown are the RBE and the OER for kidney cells as a function of depth (at 10\% survival). The variation in OER and $\mathrm{RBE}$ over the tumor region is a reflection of the variation in the energy spectrum 


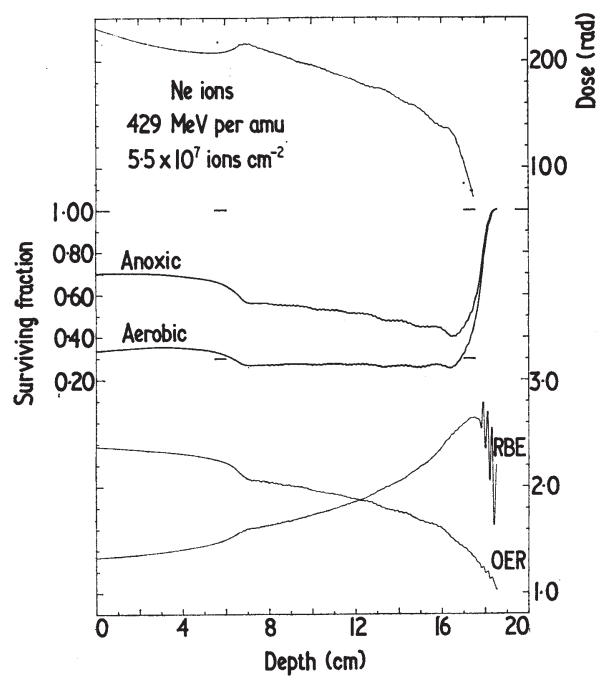

Figure 16. Ne ions, $10 \mathrm{~cm}$ ridge filter, single port.

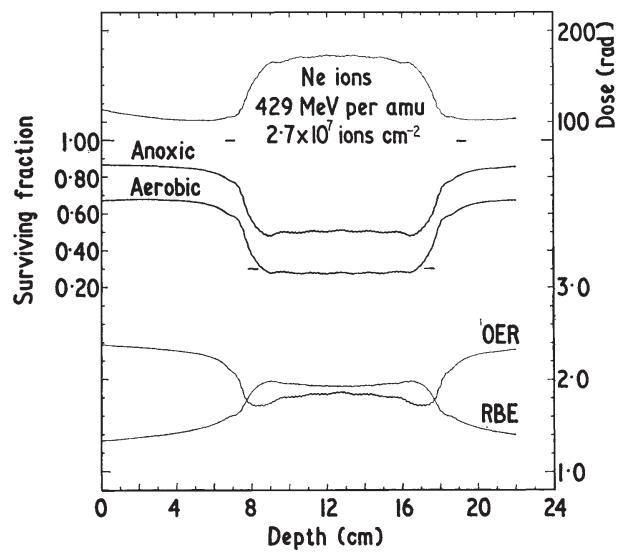

Figure 17. Ne ions, $10 \mathrm{~cm}$ ridge filter, double port.

of the dispersed beam, especially in the single port irradiations. Since symmetrically opposed port irradiations may not always be appropriate, the variation of OER with depth in a single port irradiation (Figures 7, 14, and 16) is of interest.

\section{Discussion}

For calculations in the present work it is assumed that the critical constraint upon the therapist is that $30 \%$ of normal (i.e., aerobic) cells in the tumor region must survive each dose fraction. Kidney cells in culture have been taken to be representative of the tissue irradiated, and so all calculations have been normalized to a fluence in which $30 \%$ of the aerobically irradiated kidney cells in the tumor region survive. The 
difference between two modes of irradiation may then be characterized by two numbers, the anoxic-aerobic survival ratio (AAR) in the tumor region, $A$, and $B$, the surviving fraction of aerobically irradiated cells $\left(N / N_{0}\right.$ (aerobic)) at the surface. We have no guidance from clinical experience as to the manner in which these two numbers may be combined to yield a figure of merit for a radiation technique. It is clear that one wishes both $A$ and $B$ to be as close to unity as possible, but it is not clear what value to place on a $10 \%$ decrement in $A$ at the expense of a $10 \%$ decrement in $B$, for example. If the number $A$ is of questionable importance, the choice is clearly in favor of pions, or deuterons or helium ions. If $B$ is of questionable importance, then irradiation with neon ions is in order. Ions of higher $Z$ would give an even lower value of $A$; but there are problems with beam attenuation and fragmentation. The best compromise seems to lie with pions, which give the value of AAR in the tumor region that can be achieved with oxygen ions, and a better value of the survival at surface than can be achieved with deuterons. If a clinical trial is to be used to answer questions about the relative importance of $A$ and $B$, then it would be of interest to compare pions with oxygen ions, for the AAR in the tumor region is very similar, though surface survival favors pions, or to compare pions with deuterons, where there is a marked difference in the AAR in the tumor region.

We thank Rose Ann Nelson for her help in the course of these investigations and in the preparation of the manuscript for publication. This work was supported by the National Science Foundation (RANN) and the United States Atomic Energy Commission.

\section{References}

Alper, T. 1973 Br. Med. Bull. 293

Barendsen, G. W., and Broerse J. J. 1966 Nature, Lond. 212722

Barendsen, G. W., and Broerse, J. J. 1968 Biophysical Aspects of Radiation Quality (Vienna: IAEA)

Boone, M. L., and Wiley, A. L. 1971 IEEE Trans Nucl. Sci. NS-18 36

Butts J. J., and Katz, R. 1967 Radiat. Res. 30855

Caswell, R. S., and Coyne, J. J. 1972 Radiat. Res. 52448

Catterall, M., Rogers C., Thomlinson, R. H., and Field, S. B. 1971 Br. J. Radiol. 44603

Evans, R. D. 1955 The Atomic Nucleus (New York: McGraw-Hill)

Guthrie, M. P., Alsmiller, R. G., Jr., and Bertini, H. W. 1968 Nucl. Instrum. Meth. 6629 Katz R., Ackerson B., Homayoonfar M. and Sharma S. C. 1971 Radiat. Res. 47402

Katz, R., and Kobetich, E. J. 1969 Phys. Rev. 186344

Katz, R., and Sharma, S. C. 1973 Nucl. Instrum. Meth. 11193

Katz, R., Sharma, S. C., and Homayoonfar, M. 1972 Health Phys. 23740

Nias, A. H. W., Greene, D., Fox M., and Thomas, R. L. 1967 Int. J. Radiat. Biol. 13449

Raju, M. R., Gnanapurani, M., Martins, B., Howard, J., and Lyman, J. T. 1972 Radiology 102425

Raju, M. R., Gnanapurani, M., Richman, C., Martins, B. I., and Barendsen, G. W. 1972 Br. J. Radiol. 45 178

Tobias, C. A., Lyman, J. T., and Lawrence, J. H. 1972 Progress in Nuclear Medicine ed. J. H. Lawrence 
(New York: Grune and Stratton)

Todd, P. W. 1966 Med. Coll. Virginia Q. 12

Todd, P., Schroy, C. B., Vosburgh, K. G., and Schimmerling, W. 1971 Science, N.Y. 1741127

Turner, J. E., Dutrannois, J., Wright, H. A., Hamm, R. N., Baarli, J., Sullivan, A. H., Berger, M. J., and Selzter, S. M. 1972 Radiat. Res. 52229

\section{Résumé}

Particules lourdes en thérapie; une application de la théorie de trace

On a calculé la survie, l'OER et le RBE (efficacité biologique relative) pour les cellules de HeLa, de leucémie et rénales, après l'irradiation aux neutrons de $14 \mathrm{MeV}$, aux faisceaux de pions et faisceaux d'ions lourds, diffusés par des filtres de faîte. On a employé dans les calculs des simples modèles de faisceaux ainsi que la théorie de rayons delta de la survie de cellules dans une ambiance de radiation mixte. Ces méthodes d'irradiation peuvent être employées en radiothérapie.

\section{Zusammenfassung}

Schwere Teilchen in der Therapie; eine Anwendung der Spurtheorie

Man berechnet das Überleben, OER (oxygen enhancement ratio) und RBW (relative biologische Wirksamkeit) für die HeLa-, Leukämie-, und Nierenzellen, nach der vorangehenden Bestrahlung mit $14 \mathrm{MeV}-N e u t r o n e n$, Pi-Mesonenstrahlen, und Schwerionenstrahlen, welche mittels der "ridge filter" gestreut wurden. Es wurden einfache Strahlenmodelle sowie die Delta-strahl-Theorie des Zellüberlebens in einer Umgebung mit gemischter Strahlung angewandt. Diese Bestrahlungsverfahren finden mögliche Anwendungen in der Strahlentherapie.

\section{Резюме}

Тяжелые частицы в терапии; применене теории следов

Расчетываются выживание, отношение повышения кислорода иотносительная биологическая эффективность для HeLa клеток, лейкемических и почечных клеток после облучения нейтронами с энергией в 14 Мэв, учками пи-мезонов и пучками тяжелых ионов, рассеянными при помощи бороздковых фильтров. В расчетах применяюся простые модели пучков и основанная на дельта-частицах теория выживания клеток в среде смешанного излучения. Эти методы облучения могут применяться в радиотерапии. 